\title{
Management appropriateness and outcomes of patients with acute pulmonary embolism
}

\author{
David Jiménez $\mathbb{1}^{1,11}$, Behnood Bikdeli ${ }^{2,3,11}$, Deisy Barrios', Raquel Morillo', \\ Rosa Nieto ${ }^{1}$, Ina Guerassimova ${ }^{1}$, Alfonso Muriel ${ }^{4}$, Luis Jara-Palomares (1) ${ }^{5}$, \\ Lisa Moores ${ }^{6}$, Victor Tapson ${ }^{7}$, Roger D. Yusen ${ }^{8}$ and Manuel Monreal ${ }^{9,10}$ for the \\ RIETE investigators
}

Affiliations: ${ }^{1}$ Respiratory Dept, Hospital Ramón y Cajal and Dept of Medicine, Universidad de Alcalá (IRYCIS), Madrid, Spain. ${ }^{2}$ Division of Cardiology, Dept of Medicine, Columbia University Medical Center, New YorkPresbyterian Hospital, New York, NY, USA. ${ }^{3}$ Center for Outcomes Research and Evaluation (CORE), Yale University School of Medicine, New Haven, CT, USA. ${ }^{4}$ Biostatistics Dept, Hospital Ramón y Cajal (IRYCIS), CIBERESP, Madrid, Spain. ${ }^{5}$ Respiratory Dept, Hospital Virgen del Rocío, Seville, Spain. ${ }^{6}$ F. Edward Hebert School of Medicine, Uniformed Services University, Bethesda, MD, USA. ${ }^{7}$ Dept of Medicine, Cedars-Sinai Medical Center, Los Angeles, CA, USA. ${ }^{8}$ Division of Pulmonary and Critical Care Medicine and Division of General Medical Sciences, Washington University School of Medicine, St Louis, MO, USA. ${ }^{9}$ Dept of Internal Medicine, Hospital Universitari Germans Trias i Pujol, Barcelona, Spain. ${ }^{10}$ Dept of Medicine, Universidad Católica de Murcia, Murcia, Spain. ${ }^{11}$ These authors contributed equally.

Correspondence: D. Jiménez, Respiratory Dept, Hospital Ramón y Cajal, Colmenar Road Km. 9,100, 28034 Madrid, Spain. E-mail: djimenez.hrcagmail.com

@ERSpublications

Management that does not adhere to guidelines is associated with worse outcomes in patients with acute PE http://ow.ly/vxvu30jkKuM

Cite this article as: Jiménez D, Bikdeli B, Barrios D, et al. Management appropriateness and outcomes of patients with acute pulmonary embolism. Eur Respir J 2018; 51: 1800445 [https://doi.org/10.1183/ 13993003.00445-2018].

ABSTRACT The impact of adherence to published guidelines on the outcomes of patients with acute pulmonary embolism (PE) has not been well defined by previous studies.

In this prospective cohort study of patients admitted to a respiratory department $(n=2096)$, we evaluated whether patients with PE had better outcomes if they were acutely managed according to international guidelines. Outcomes consisted of all-cause mortality, PE-related mortality, recurrent venous thromboembolism (VTE) and major bleeding events during the first month of follow-up after diagnosis.

Overall, 408 patients (19\% (95\% CI 18-21\%)) did not receive guideline-adherent PE management. Patients receiving non-adherent management were significantly more likely to experience all-cause mortality (adjusted odds ratio (OR) 2.39 (95\% CI 1.57-3.61) or PE-related mortality (adjusted OR 5.02 (95\% CI 2.42-10.42); $\mathrm{p}<0.001)$ during follow-up. Non-adherent management was also a significant independent predictor of recurrent VTE (OR 2.19 (95\% CI 1.11-4.32); p=0.03) and major bleeding (OR 2.65 (95\% CI 1.66-4.24); $\mathrm{p}<0.001$ ). An external validation cohort of 34380 patients with PE from the RIETE registry confirmed these findings.

PE management that does not adhere to guidelines for indications related to anticoagulation, thrombolytics and inferior vena cava filters is associated with worse patient outcomes. 


\section{Introduction}

Pulmonary embolism (PE) occurs commonly and affects 29-78 adults per 100000 person-years [1, 2]. PE is the third most common vascular cause of death, after myocardial infarction and stroke, and the leading preventable cause of death in hospitalised patients [3]. To guide and assist in choosing the appropriate initial PE treatments, scientific societies have published several clinical guidelines [4-6].

To date, adherence to guidelines often remains low, causing omission of recommended therapies, or providing extra interventions that might not necessarily help but can contribute to preventable harm, suboptimal patient outcomes or experiences and waste of resources [7]. Acceptance of and compliance with guidelines might be associated with better prognosis for patients with acute PE, since such therapies might lead directly into better outcomes, might act as a marker for better quality of care, or both [8].

Unfortunately, large studies have not validated the association between the adherence to PE guidelines in routine clinical practice and patient outcomes. Therefore, we identified a few key elements in the management of acute PE and aimed to assess whether clinicians routinely used guideline-recommended treatments for managing patients who have this condition. We also aimed to identify the predictors of guideline non-adherent PE management and sought to determine if guideline non-adherent management correlated with pertinent clinical outcomes after accounting for other clinical factors. The results were validated in the Registro Informatizado de la Enfermedad TromboEmbólica (the RIETE registry).

\section{Methods}

For this prospective observational cohort study, we report the study methods and results in accordance with the STrengthening the Reporting of OBservational studies in Epidemiology (STROBE) guidelines [9].

\section{Patients, setting, and eligibility criteria}

For this study, we screened patients who presented to the Emergency Department of Ramón y Cajal Hospital (Madrid, Spain) with symptoms of acute PE from January 01, 2003 until December 31, 2016 (figure 1).

For confirmation of the diagnosis of $\mathrm{PE}$, we required an intraluminal filling defect on PE-protocol contrast-enhanced helical chest computed tomography (CT) [10]; a high probability ventilation-perfusion scan according to the criteria of the Prospective Investigation of Pulmonary Embolism Diagnosis (PIOPED) [11]; or a non-diagnostic ventilation-perfusion lung scan and confirmed lower limb deep vein thrombosis (DVT) on venous compression ultrasound [12]. The only exclusion criterion was treatment with therapeutic doses of anticoagulants initiated $\geqslant 24 \mathrm{~h}$ prior to eligibility assessment.

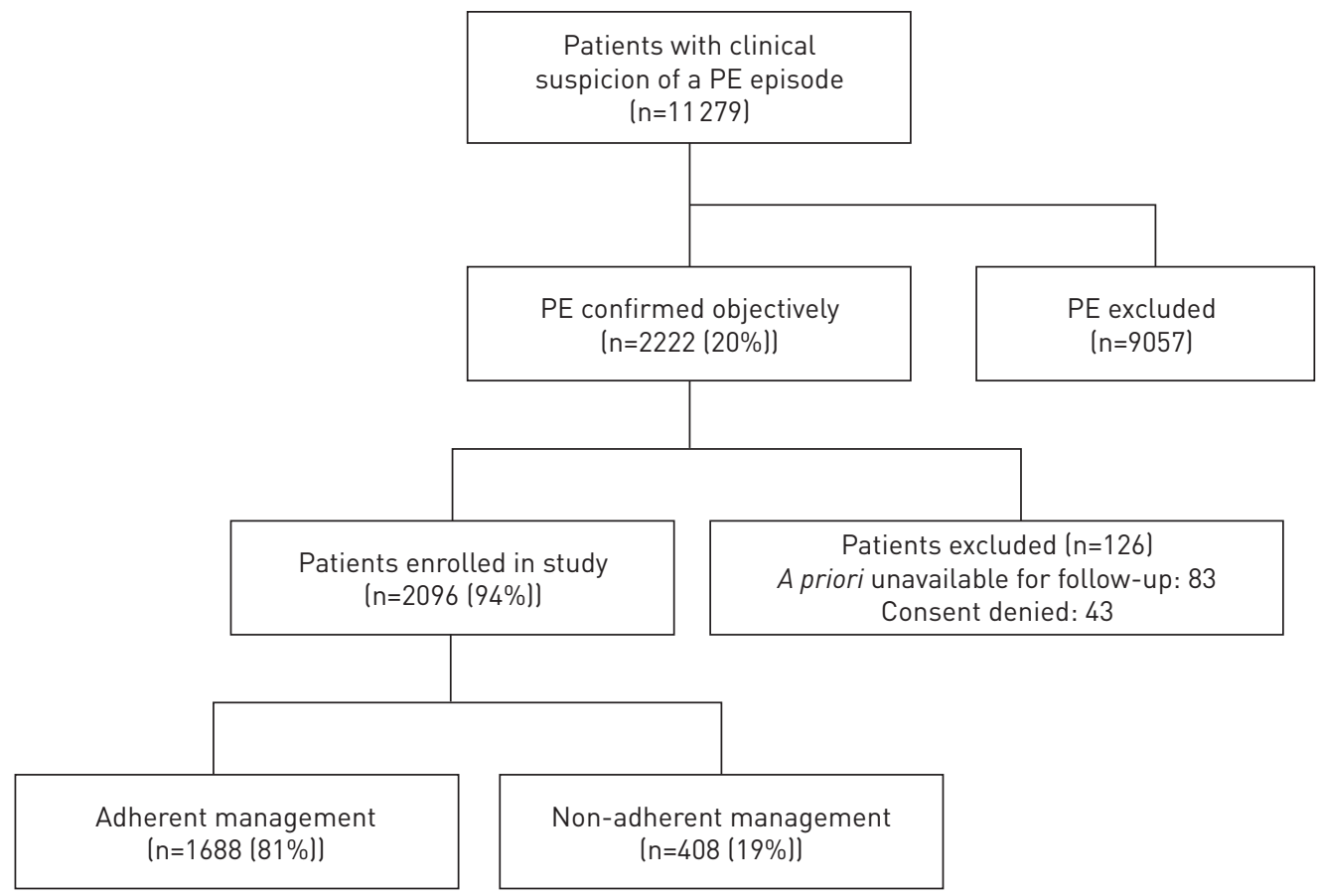

FIGURE 1 Patient flow diagram. PE: pulmonary embolism. 


\section{Adherence to guidelines}

Acute therapy after hospitalisation was evaluated for adherence or non-adherence to the management recommended by guidelines $[4-6,13]$. Two investigators independently analysed each patient's chart and classified the management as adherent or non-adherent. Discrepancies in adherence determination were resolved by consensus after asking the opinion of a third investigator. Deviation from guidelines defined non-adherent management and was defined as any of the following: 1) Use of intravenous unfractionated heparin (UFH) in a patient without severe renal failure (i.e. creatinine clearance $<30 \mathrm{~mL} \cdot \mathrm{min}^{-1}$ ), without severe obesity (i.e. body weight $>120 \mathrm{~kg}$ ) and without unstable PE (defined as cardiogenic shock, systolic blood pressure (SBP) $<90 \mathrm{mmHg}$, or use of inotropic or vasopressor support) [6]; or use of low-molecular-weight heparin (LMWH) in a patient with severe renal failure, severe obesity, or unstable $\mathrm{PE}$ [13]. 2. Use of thrombolytic therapy in a haemodynamically stable patient who did not deteriorate soon after diagnosis $[5,6]$; or no use of thrombolytic therapy in a haemodynamically unstable patient without major contraindications owing to bleeding risk [4-6]. 3. Insertion of an inferior vena cava filter in a patient without a contraindication to anticoagulant therapy [4-6]; or no insertion of an inferior vena cava filter in a patient with a contraindication to anticoagulant therapy [4-6].

\section{Study outcome measures}

Outcomes were assessed during the first month after the diagnosis of acute PE. We used all-cause mortality as the primary outcome of the study (mortality being assessed using patient or proxy interviews and/or hospital chart review). Pre-specified secondary outcomes included PE-specific mortality, recurrent symptomatic venous thromboembolism (VTE) and major bleeding. Two investigators independently adjudicated the cause of death as 1) definite fatal PE, 2) possible fatal PE, or 3) death from other causes. For deaths confirmed by autopsy or those following a clinically severe PE (either initially or shortly after an objectively confirmed recurrent event), the adjudicators judged death as a definite fatal PE in the absence of any alternative diagnosis. Possible fatal PE consisted of death in a patient who died suddenly or unexpectedly after the diagnosis of PE. In cases of disagreement between the reviewers, a third reviewer established the final cause of death by consensus with the other reviewers.

Recurrent symptomatic VTE was defined as a recurrent PE, or a new or recurrent distal or proximal lower extremity DVT, within 1 month of entry to the study with acute PE. For the recurrent PE diagnosis, we required the presence of a new perfusion defect involving $75 \%$ or more of a lung segment on V/Q scintigraphy, or a new intraluminal filling defect or an extension of a previous filling defect on PE-protocol chest CT [10]. For a new or recurrent DVT, we required the appearance of a new noncompressible vein segment, or a $4-\mathrm{mm}$ or more increase in the diameter of a thrombus on complete compression ultrasound (CCUS) [14].

We defined major bleeding episodes as those that required a transfusion of at least 2 units of blood, were retroperitoneal, spinal or intracranial, or were fatal [15].

\section{Statistical analyses}

We used the Chi-squared test to compare categorical data between patients who received appropriate or inappropriate management. We used the T-test for parametric comparisons between the two groups and the Mann-Whitney U-test when the data were non-parametric.

To estimate the outcomes of time to death and time to VTE recurrence, Kaplan-Meier probabilities were computed [16] and differences between the groups were assessed with the log-rank test. We used logistic regression to assess if the variable of adherence to guidelines had an independent association with 30-day all-cause mortality after adjusting for other variables that had a p-value of less than 0.05 in the univariate analyses. We used a manual backward stepwise approach to develop the multivariate models. Statistical significance was defined as a two-tailed $\mathrm{p}$-value of $<0.05$ for all analyses. Analyses were performed using SPSS version 18.0 for the PC (SPSS Inc, Chicago, IL, USA).

We performed several sensitivity analyses and, since some of the criteria that shaped the definition for inappropriate management might be more representative than others, we repeated analyses for the most agreed criteria (i.e. no thrombolysis in an unstable patient; no filter in a patient with contraindication to anticoagulation; and no UFH in a patient with severe renal insufficiency, severe obesity, or unstable PE) alone and in combination. We then examined the association between inappropriate management and outcomes for three separate time periods (2003-2008, 2009-2014 and 2015-2016). Finally, we repeated all analyses for the secondary endpoints.

To ensure that our findings were replicable, we used patient data from the Registro Informatizado de la Enfermedad TromboEmbólica (RIETE). The study design and patient eligibility criteria for RIETE data 
TABLE 1 Clinical outcomes according to adherent or non-adherent management of acute pulmonary embolism (PE)

\begin{tabular}{|c|c|c|c|c|c|}
\hline \multirow[t]{2}{*}{ Variable } & \multirow{2}{*}{$\begin{array}{l}\text { Patients } \\
\text { (n=2096) }\end{array}$} & \multicolumn{4}{|c|}{ Clinical outcome } \\
\hline & & $\begin{array}{l}\text { All-cause } \\
\text { mortality }\end{array}$ & $\begin{array}{l}\text { PE-related } \\
\text { mortality }\end{array}$ & $\begin{array}{l}\text { Recurrent } \\
\text { VTE }\end{array}$ & $\begin{array}{c}\text { Major } \\
\text { bleeding }\end{array}$ \\
\hline $\begin{array}{l}\text { No UFH in a patient with severe renal insufficiency, } \\
\text { severe obesity, unstable PE }\end{array}$ & $112 / 538(20.8)$ & $15 / 112(13.4)$ & $9 / 112(8.0)$ & $3 / 112(2.7)$ & $3 / 112(2.7)$ \\
\hline $\begin{array}{l}\text { UFH in a patient without severe renal insufficiency, } \\
\text { severe obesity, unstable PE }\end{array}$ & $54 / 1558(3.5)$ & $11 / 54(20.4)$ & $8 / 54(14.8)$ & $3 / 54(5.6)$ & $4 / 54(7.4)$ \\
\hline No thrombolysis in an unstable patient & $117 / 165(70.9)$ & $20 / 117(17.1)$ & 15/117 (12.8) & $1 / 117(0.8)$ & $6 / 117(5.1)$ \\
\hline Thrombolysis in a stable patient & $44 / 1931(2.3)$ & $1 / 44(2.3)$ & $1 / 44(2.3)$ & $1 / 44(2.3)$ & $3 / 44(6.8)$ \\
\hline \multicolumn{6}{|l|}{ Inferior vena cava filter } \\
\hline $\begin{array}{l}\text { No filter in a patient with contraindication to } \\
\text { anticoagulation }\end{array}$ & $167 / 181(92.3)$ & $28 / 167(16.8)$ & $12 / 167(7.2)$ & $6 / 167(3.6)$ & $9 / 167(5.4)$ \\
\hline $\begin{array}{l}\text { Filter in a patient without contraindication to } \\
\text { anticoagulation }\end{array}$ & $35 / 1915$ (1.8) & $5 / 35(14.3)$ & $2 / 35(5.7)$ & $3 / 35(8.6)$ & $10 / 35(28.6)$ \\
\hline
\end{tabular}

Data is presented as $\mathrm{n} / \mathrm{n}(\%)$. VTE: venous thromboembolism; UFH: unfractionated heparin.

have been described elsewhere [17]. The validation cohort for this study consisted of a separate group of 34380 patients from the RIETE registry with acute symptomatic PE.

\section{Results \\ Study sample}

Of the 11279 patients who had suspected PE and underwent screening for the study, 19.7\% (2222 out of 11279 patients) had an objective diagnosis of PE. Of these, we excluded 5.7\% (126 out of 2222 patients) because they refused to give informed consent $(n=43)$ or were unavailable for follow-up ( $n=83$ ) (figure 1). The eligible study cohort of 2096 patients included 1092 women and 1004 men.

\section{Baseline characteristics}

Overall, 1688 patients (81\% (95\% CI 79-82\%)) received guideline-adherent anticoagulant, inferior vena cava filter, or thrombolysis management of acute PE and 408 did not. Adherence to anticoagulant use as recommended in the guidelines was 92\% (95\% CI 91-93\%) (1930 out of 2096 patients), while the use or no use of thrombolytic therapy occurred according to guideline recommendations in $92 \%$ (95\% CI $91-$ 93\%) of cases (1935 out of 2096 patients). Furthermore, patients did or did not undergo inferior vena cava filter treatment according to guideline recommendations $90 \%$ (95\% CI 89-92\%) of the time (1894 out of 2096 patients) (table 1).

Patients with and those without guideline-adherent management differed significantly in pre-existing medical conditions and in relevant clinical, physiologic and laboratory parameters (table 2). Patients who received non-adherent care had a higher prevalence of immobilisation or recent major bleeding compared to those who received guideline-adherent care. Patients receiving non-guideline-adherent care also had more haemodynamic compromise, with lower SBP, higher heart rate (HR) and more frequent hypoxaemia and syncope (table 2). They also had a higher prevalence of anaemia and renal insufficiency. In the multivariable model, recent major bleeding (OR 50.87 (95\% CI 9.07-285.25)), HR $\geqslant 110$ beats. $\mathrm{min}^{-1}$ (OR 2.27 (95\% CI 1.31-3.94)), SBP <90 mmHg (OR 9.73 (95\% CI 2.98-31.79)), elevated creatinine (OR 7.72 (95\% CI 4.22-14.13)), elevated troponin (OR 1.50 (95\% CI 1.09-2.05)) and elevated brain natriuretic peptide (BNP) (OR 1.74 (95\% CI 1.02-2.96)) remained significantly associated with non-adherent management.

\section{Outcomes}

Mortality

Overall, 140 out of 2096 patients (6.7\% (95\% CI 5.6-7.8\%)) died during the first month of follow-up. PE (definite $(n=23)$ or possible $(n=39))$ was the primary cause of death $(3.0 \% ; 62$ out of 2096 patients), whereas less frequent causes of death included cancer (1.5\%; 31 out of 2096 patients), infection $(0.9 \% ; 19$ out of 2096 patients), major bleeding ( $0.3 \%$; seven out of 2096 patients), other diseases ( $0.8 \%$; 17 out of 2096 patients) and unknown causes ( $0.2 \%$; four out of 2096 patients). 
TABLE 2 Baseline characteristics and treatment information for patients with acute symptomatic pulmonary embolism (PE)

\begin{tabular}{|c|c|c|c|c|}
\hline \multirow[t]{2}{*}{ Characteristics } & \multirow{2}{*}{$\begin{array}{l}\text { Patients } \\
\text { (n=2096) }\end{array}$} & \multicolumn{2}{|c|}{ Management } & \multirow[t]{2}{*}{ p-value } \\
\hline & & $\begin{array}{l}\text { Adherent } \\
\text { ( } n=1688 \text { ) }\end{array}$ & $\begin{array}{l}\text { Non-adherent } \\
\text { (n=408) }\end{array}$ & \\
\hline \multicolumn{5}{|l|}{ Clinical characteristics } \\
\hline Age years & $68.7 \pm 16.6$ & $68.4 \pm 16.8$ & $69.9 \pm 15.9$ & 0.09 \\
\hline Age $>65$ years & $1394(67)$ & $1108(66)$ & $286(70)$ & 0.09 \\
\hline Male sex & $1004(48)$ & $801(47)$ & $203(50)$ & 0.41 \\
\hline $\mathrm{BMI} \mathrm{kg} \cdot \mathrm{m}^{-2}$ & $27.2 \pm 6.4$ & $27.2 \pm 6.5$ & $27.2 \pm 5.9$ & 0.98 \\
\hline Delays in diagnosis days & $5.0 \pm 11.2$ & $5.2 \pm 12.0$ & $4.1 \pm 6.6$ & $<0.01$ \\
\hline \multicolumn{5}{|l|}{ Risk factors for VTE } \\
\hline History of VTE & 249 (12) & $212(13)$ & $37(9.1)$ & 0.05 \\
\hline Cancer $\#$ & $432(21)$ & $352(21)$ & $80(20)$ & 0.63 \\
\hline Recent surgery" & $188(9.0)$ & $146(8.6)$ & $42(10)$ & 0.29 \\
\hline Immobilization $^{+}$ & $412(20)$ & $296(17)$ & $116(28)$ & $<0.001$ \\
\hline \multicolumn{5}{|l|}{ Comorbid diseases } \\
\hline Recent major bleeding" & 70 (3.3) & $8(0.5)$ & $62(15)$ & $<0.001$ \\
\hline COPD & $169(8.1)$ & 140 (8.3) & $29(7.1)$ & 0.48 \\
\hline Congestive heart failure & $116(5.5)$ & $86(5.1)$ & $30(7.3)$ & 0.09 \\
\hline Concomitant DVT (n=1630) & $916(56)$ & $738(55)$ & 178 (59) & 0.25 \\
\hline \multicolumn{5}{|c|}{ Clinical symptoms and signs at presentation } \\
\hline Syncope & $300(14)$ & $225(13)$ & $75(18)$ & 0.01 \\
\hline Chest pain & $936(45)$ & $777(45)$ & $159(44)$ & 0.58 \\
\hline Dyspnoea & $1514(72)$ & $1223(72)$ & $291(71)$ & 0.67 \\
\hline $\mathrm{HR} \geqslant 110 \mathrm{bpm}$ & $426(20)$ & $313(18)$ & $113(28)$ & $<0.001$ \\
\hline $\begin{array}{l}\text { Arterial oxyhaemoglobin } \\
\text { saturation }<90 \%\end{array}$ & $563(27)$ & $428(25)$ & $135(33)$ & $<0.01$ \\
\hline $\mathrm{SBP}<90 \mathrm{mmHg}$ & $75(3.6)$ & $11(0.6)$ & $64(16)$ & $<0.001$ \\
\hline \multicolumn{5}{|l|}{ Cardiac biomarkers } \\
\hline $\mathrm{BNP}>100 \mathrm{pg} \cdot \mathrm{mL}^{-1}(\mathrm{n}=805)$ & $379(47)$ & $300(43)$ & $79(68)$ & $<0.001$ \\
\hline $\mathrm{cTnl}>0 \mathrm{ng} \cdot \mathrm{mL}^{-1}(\mathrm{n}=1564)$ & $460(29)$ & $311(24)$ & $149(51)$ & $<0.001$ \\
\hline \multicolumn{5}{|c|}{ Simplified Pulmonary Embolism Severity Index (sPESI) } \\
\hline Low-risk & $638(30)$ & $551(33)$ & $87(21)$ & $<0.001$ \\
\hline High-risk & $1458(70)$ & $1137(67)$ & $321(79)$ & $<0.001$ \\
\hline \multicolumn{5}{|l|}{ Laboratory findings } \\
\hline Haemoglobin $\mathrm{g} \cdot \mathrm{dL}^{-1}$ & $13.2 \pm 2.0$ & $13.3 \pm 1.9$ & $12.8 \pm 2.2$ & $<0.001$ \\
\hline Creatinine $>2 \mathrm{mg} \cdot \mathrm{dL}^{-1}$ & $78(3.7)$ & $2(0.1)$ & $76(19)$ & $<0.001$ \\
\hline
\end{tabular}

Data is presented as $\mathrm{n}(\%)$ or mean \pm SD. BMI: body mass index; VTE: venous thromboembolism; COPD: chronic obstructive pulmonary disease; DVT: deep vein thrombosis; HR: heart rate; SBP: systolic blood pressure; BNP: brain natriuretic peptide; cTnl: cardiac troponin I; ${ }^{\#}$ : active or under treatment in the last year; ${ }^{\text {ๆ: }}$ in the previous month; ${ }^{+}$: immobilised patients are defined in this analysis as non-surgical patients who were immobilised (i.e. total bed rest with bathroom privileges) for $\geqslant 4$ days in the month prior to PE diagnosis.

Eighty-five deaths (85 out of 1688 patients; 5.0\% (95\% CI 4.0-6.2\%)) occurred in the group of patients who received guideline-adherent management, whereas 55 deaths (55 out of 408 patients; $13.5 \%$ (95\% CI 10.3-17.2\%)) occurred in the group of patients who received non-adherent management (absolute difference $8.5 \%$ (95\% CI 5.3-12.2\%); $\mathrm{p}<0.001$ ). Patients with acute PE and non-adherent management had a significantly higher cumulative mortality than patients with acute PE and adherent management $(\mathrm{p}<0.001$ (log-rank test); figure 2).

In univariate analyses, non-adherent management (OR 2.94 (95\% CI 2.05-4.20)), congestive heart failure (OR 2.39 (95\% CI 1.37-4.18)), recent major bleeding (OR 3.06 (95\% CI 1.60-5.84)), presence of concomitant DVT (OR 1.78 (95\% CI 1.19-2.69)), SBP <90 mmHg (OR 3.79 (95\% CI 2.09-6.87)), HR $\geqslant 110$ beats $\mathrm{min}^{-1}$ (OR 1.51 (95\% CI 1.02-2.22)), arterial oxyhaemoglobin saturation <90\% (OR 1.97 (95\% CI 1.38-2.80)), dyspnoea (OR 1.83 (95\% CI 1.17-2.85)), cancer (OR 3.63 (95\% CI 2.56-5.16)) and immobilisation (OR 1.51 (95\% CI 1.10-2.06)) at the time of acute PE diagnosis were significantly associated with death during follow-up (table 1 and table 3). In the multivariate analysis, recent major bleeding (OR 1.66 (95\% CI 0.83-3.35); p=0.15) and SBP <90 mmHg (OR 2.12 (95\% CI 1.11-4.05); 
Number at risk

Non-adherent management

Adherent management

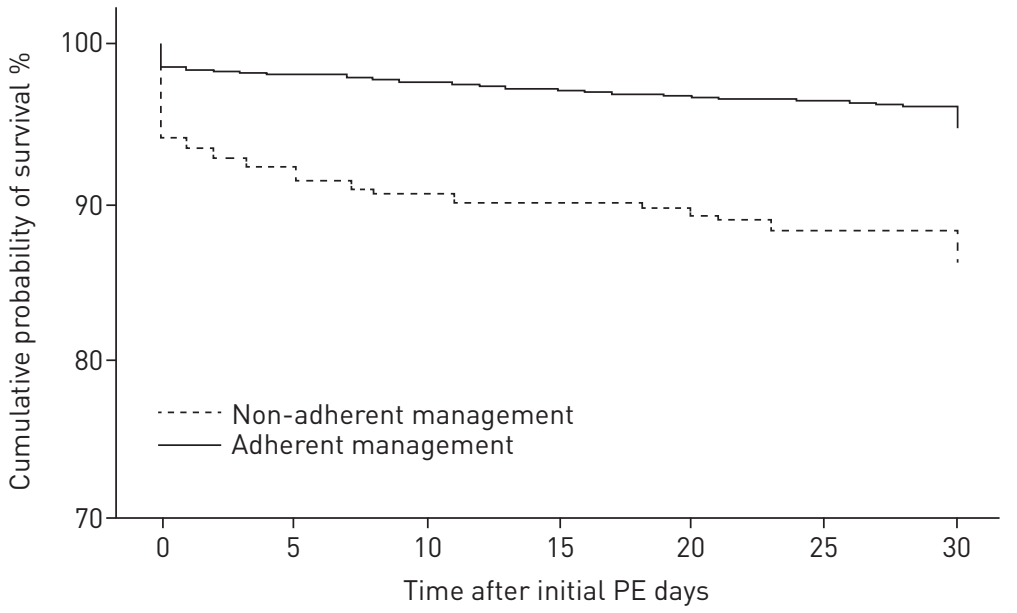

Log rank $p<0.001$

$\begin{array}{cccc}408 & 369 & 364 & 353 \\ 1688 & 1649 & 1633 & 1603\end{array}$

FIGURE 2 Cumulative probability of survival stratified by adherence to guidelines. PE: pulmonary embolism.

$\mathrm{p}=0.02$ ) were confounding variables for the association between non-adherent management and all-cause mortality during follow-up (adjusted OR 2.39 (95\% CI 1.57-3.61); p<0.001) (table 1 and table 3). In univariate analysis, non-adherent management (OR 5.38 (95\% CI 3.23-9.01)) at the time of acute PE diagnosis was significantly associated with PE-related death during follow-up. After adjustment, non-adherent management remained independently significantly associated with PE-related death (OR 5.02 (95\% CI 2.42-10.42); $\mathrm{p}<0.001)$ (table 1 and table 4).

TABLE 3 Unadjusted and adjusted odds ratios (ORs) for overall mortality in patients with acute symptomatic pulmonary embolism (PE)

\begin{tabular}{|c|c|c|c|c|}
\hline \multirow[t]{2}{*}{ Risk factor } & \multicolumn{2}{|c|}{ OR $(95 \% \mathrm{CI})$} & \multicolumn{2}{|c|}{ p-value } \\
\hline & Unadjusted & Adjusted & Unadjusted & Adjusted \\
\hline Age (per year) & $1.02(1.01-1.04)$ & - & $<0.001$ & - \\
\hline Male gender & $0.86(0.61-1.21)$ & - & 0.38 & - \\
\hline Non-adherent management & $2.94(2.05-4.20)$ & $2.39(1.57-3.61)$ & $<0.001$ & $<0.001$ \\
\hline Anticoagulant use & $2.96(1.87-4.68)$ & $2.63(1.65-4.21)$ & $<0.001$ & $<0.001$ \\
\hline Thrombolytic use & $2.29(1.40-3.75)$ & $1.45(0.77-2.72)$ & $<0.01$ & 0.25 \\
\hline Filter use & $3.26(2.14-4.97)$ & $3.14(1.93-5.11)$ & $<0.001$ & $<0.001$ \\
\hline COPD & $1.64(0.96-2.80)$ & - & 0.07 & - \\
\hline Congestive heart failure & $2.39(1.37-4.18)$ & - & $<0.01$ & - \\
\hline Recent major bleeding ${ }^{\#}$ & $3.06(1.60-5.84)$ & $1.66(0.83-3.35)$ & $<0.01$ & 0.15 \\
\hline Presence of DVT & $1.78(1.19-2.69)$ & - & $<0.01$ & - \\
\hline SBP $<90 \mathrm{mmHg}$ & $3.79(2.09-6.87)$ & $2.12(1.11-4.05)$ & $<0.001$ & 0.02 \\
\hline$H R \geqslant 110 \mathrm{bpm}$ & $1.51(1.02-2.22)$ & - & 0.04 & - \\
\hline Arterial oxyhaemoglobin saturation $<90 \%$ & $1.97(1.38-2.80)$ & - & $<0.001$ & - \\
\hline Dyspnoea & $1.83(1.17-2.85)$ & - & $<0.01$ & - \\
\hline Chest pain & $0.51(0.35-0.74)$ & - & $<0.001$ & - \\
\hline Syncope & $0.49(0.26-0.92)$ & - & 0.03 & - \\
\hline Cancer ${ }^{\pi}$ & $3.63(2.56-5.16)$ & - & $<0.001$ & - \\
\hline Immobilization $^{+}$ & $1.51(1.10-2.06)$ & - & 0.01 & - \\
\hline
\end{tabular}

The total number of subjects evaluated was 2096, with 140 deaths (the final model Chi-squared result was 38.78; <0.001). COPD: chronic obstructive pulmonary disease; DVT: deep vein thrombosis; SBP: systolic blood pressure; HR: heart rate. \#: in the previous month. ": active or under treatment in the last year. ${ }^{+}$: immobilised patients are defined in this analysis as non-surgical patients who were immobilised (i.e. total bed rest with bathroom privileges) for $\geqslant 4$ days in the month prior to PE diagnosis. 
TABLE 4 Unadjusted and adjusted odds ratios (ORs) for pulmonary embolism (PE) related death in patients with acute symptomatic PE

\begin{tabular}{|c|c|c|c|c|}
\hline \multirow[t]{2}{*}{ Risk factor } & \multicolumn{2}{|c|}{ OR $(95 \% \mathrm{CI})$} & \multicolumn{2}{|c|}{$\mathrm{p}$-value } \\
\hline & Unadjusted & Adjusted & Unadjusted & Adjusted \\
\hline Age (per year) & $1.04(1.02-1.06)$ & - & $<0.001$ & - \\
\hline Male gender & $0.73(0.43-1.22)$ & - & 0.23 & - \\
\hline Non-adherent management & $5.38(3.23-9.01)$ & $5.02(2.42-10.42)$ & $<0.001$ & $<0.001$ \\
\hline Anticoagulant use & $4.78(2.67-8.56)$ & $4.10(2.25-7.46)$ & $<0.001$ & $<0.001$ \\
\hline Thrombolytic use & $4.53(2.50-8.20)$ & $2.70(1.25-5.83)$ & $<0.001$ & 0.01 \\
\hline Filter use & $2.86(1.55-5.29)$ & $2.36(1.15-4.86)$ & $<0.01$ & 0.02 \\
\hline COPD & $1.23(0.52-2.90)$ & - & 0.64 & - \\
\hline Congestive heart failure & $1.87(0.79-4.44)$ & - & 0.15 & - \\
\hline Recent major bleeding $\#$ & $2.05(0.72-5.81)$ & - & 0.18 & - \\
\hline Presence of DVT & $2.25(1.24-4.09)$ & $3.05(1.31-7.12)$ & $<0.01$ & 0.01 \\
\hline $\mathrm{SBP}<90 \mathrm{mmHg}$ & $6.64(3.30-13.34)$ & $2.37(0.82-6.87)$ & $<0.001$ & 0.11 \\
\hline$H R \geqslant 110 \mathrm{bpm}$ & $2.06(1.20-3.52)$ & - & $<0.01$ & - \\
\hline Arterial oxyhaemoglobin saturation $<90 \%$ & $2.82(1.70-4.69)$ & - & $<0.001$ & - \\
\hline Dyspnoea & $1.46(0.79-2.72)$ & - & 0.23 & - \\
\hline Chest pain & $0.58(0.34-1.00)$ & - & 0.05 & - \\
\hline Syncope & $0.88(0.42-1.87)$ & - & 0.75 & - \\
\hline Cancer ๆ & $2.02(1.18-3.46)$ & - & 0.01 & - \\
\hline Immobilization $^{+}$ & $1.50(1.08-2.08)$ & - & 0.02 & - \\
\hline
\end{tabular}

The total number of subjects evaluated was 2096, with 62 PE related deaths (the final model Chi-squared result was 27.06; $\mathrm{p}$ 0.001). COPD: chronic obstructive pulmonary disease; DVT: deep vein thrombosis; SBP: systolic blood pressure; HR: heart rate. "\#: in the previous month. ": active or under treatment in the last year. ${ }^{+}$: immobilised patients are defined in this analysis as non-surgical patients who were immobilised $(i$. e. total bed rest with bathroom privileges) for $\geqslant 4$ days in the month prior to PE diagnosis.

\section{Recurrent venous thromboembolism}

Out of 2096 patients, 89 (4.2\%) had clinically suspected recurrent VTE during follow up and symptomatic VTE was objectively confirmed in 38 out of 2096 patients (1.8\% (95\% CI 1.3-2.5\%)). Furthermore, 28 out of 2096 patients (1.3\% (95\% CI 0.9-1.9\%)) had recurrent symptomatic PE and ten patients out of 2096 (0.5\% (95\% CI 0.2-0.9\%)) had symptomatic DVT (nine proximal and one distal).

Of the patients who received non-adherent management, 13 out of 408 (3.2\% (95\% CI 1.7-5.4\%)) had a symptomatic VTE recurrence during follow-up, whereas 25 out of 1688 patients (1.5\% (95\% CI 1.0-2.2\%)) of the patients who received guideline-adherent management experienced a symptomatic VTE recurrence (absolute difference 1.7\% (95\% CI 0.2-3.9\%); $\mathrm{p}=0.03$ ) (figure 3).

\section{Major bleeding}

Major bleeding was objectively confirmed in 79 out of 2096 patients in the cohort (3.8\% (95\% CI 3.0$4.7 \%)$ ). Of the patients who received non-adherent management, 30 out of 408 patients $(7.4 \%$ (95\% CI $5.0-10.3 \%)$ ) had major bleeding during follow-up, whereas only 49 out of 1688 patients (2.9\% (95\% CI 2.2-3.8\%)) who received adherent management experienced major bleeding (absolute difference $4.5 \%$ (95\% CI 2.1-7.5\%); $\mathrm{p}<0.001)$.

\section{Sensitivity analyses}

In the multivariate analysis, unstable patients who did not receive thrombolysis were significantly more likely to experience all-cause mortality (adjusted OR 2.09 (95\% CI 1.04-4.20); p=0.04) or PE-related morality (adjusted OR 3.69 (95\% CI 1.57-8.72); p<0.01) during follow-up. After adjustment, patients with contraindication to anticoagulation who did not receive a filter were significantly more likely to experience all-cause mortality (adjusted OR 2.68 (95\% CI 1.53-4.68); p<0.01) or PE-related mortality (adjusted OR 2.32 (95\% CI 1.04-5.14); $\mathrm{p}=0.04$ ) during follow-up. Analysis of the subgroup of patients with severe renal insufficiency, severe obesity, or unstable PE showed a statistically significant reduction in survival for patients who did not receive UFH versus those who did (OR 2.07 (95\% CI 1.16-3.72); p=0.01). After adjustment for recent major bleeding, SBP $<90 \mathrm{mmHg}$ and study period, non-adherent management remained independently significantly associated with all-cause mortality (adjusted OR 2.20 (95\% CI 1.443.38); $\mathrm{p}<0.001$ ) and PE-related mortality (adjusted OR 2.20 (95\% CI 1.44-3.38); p<0.001). 
Number at risk

Non-adherent management

Adherent management

Log rank $p<0.001$

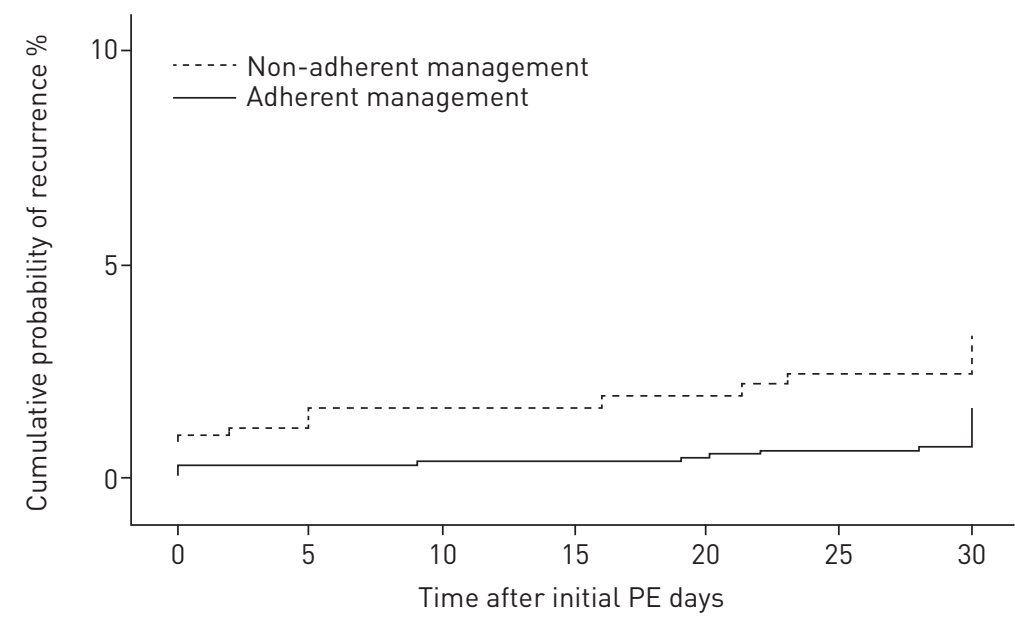

$\begin{array}{lccc}408 & 398 & 388 & 295 \\ 1688 & 1682 & 1678 & 1663\end{array}$

FIGURE 3 Cumulative probability of recurrent symptomatic venous thromboembolism (VTE) stratified by adherence to guidelines. PE: pulmonary embolism.

\section{External validation in the RIETE registry}

Compared to the 2096 patients in the original study cohort, the 34380 eligible patients from the RIETE validation cohort were significantly more likely to have younger age, previous VTE, recent surgery, immobilisation $\geqslant 4$ days, chronic pulmonary disease, congestive heart failure and concomitant DVT at the time of presentation. Elevated BNP and troponin were significantly more prevalent among patients in the RIETE cohort compared to the study cohort. However, patients in the RIETE cohort had a lower prevalence of recent major bleeding and hypoxaemia compared to patients in the study cohort. In the RIETE cohort, non-adherent management was detected in 5185 out of 34380 patients (15.1\% (95\% CI 14.7-15.5\%)), compared with 408 out of 2096 patients in the main study cohort $(19.5 \%$ (95\% CI $17.8-$ 21.2\%); absolute risk difference $4.4 \%$ (95\% CI 2.7-6.2\%)).

In RIETE, after adjusting for recent bleeding and $\mathrm{SBP}<90 \mathrm{mmHg}$ at the time of acute PE diagnosis, patients with non-adherent management had a significantly higher all-cause mortality compared to those with adherent management (adjusted OR 1.56 (95\% CI 1.36 to 1.78); p<0.001). Furthermore, after adjustment, non-adherent management had an independently significant association with PE-specific mortality (adjusted OR 2.28 (95\% CI 1.86 to 2.81 ); $\mathrm{p}<0.001$ ).

\section{Discussion}

This study showed that routine management for patients with acute symptomatic PE did not, in many cases, adhere to evidence-based guidelines for three major indications related to anticoagulation, use of thrombolytics and use of inferior vena cava filters. We demonstrated that non-adherent management strongly correlated with poor patient outcomes. The risk of death from any cause among patients with non-adherent management was about 2-times higher and the risk of PE-specific death was about 5-times higher than in patients with adherent management. Clinicians most commonly did not adhere to evidence-based therapies under two circumstances: 1) when patients were haemodynamically compromised, and 2) when patients had an increased risk of bleeding. The large RIETE validation cohort confirmed the prognostic significance of non-adherent management in patients with acute symptomatic PE.

Recent guidelines underscore the importance of the use of thrombolytic therapy for patients with acute symptomatic PE and haemodynamic instability who do not have major contraindications owing to bleeding risk $[5,6]$. Though the evidence supporting the use of thrombolysis is strongest in patients with acute PE and hypotension, in our study $67 \%$ of such high-risk patients did not receive thrombolytic therapy. Though these results may reflect real-world complexities concerning thrombolytic therapy in clinical practice, in which the risks and benefits must be weighed on a case-by-case basis, we may hypothesise that other barriers to guideline use included lack of knowledge, ambiguity, inertia and patient refusal. Alternatively, physicians in our study were appropriately very reluctant to use thrombolytic therapy 
in the setting of haemodynamically stable $\mathrm{PE}$, with only $2 \%$ of such patients receiving thrombolytic therapy. The results of the Pulmonary Embolism Thrombolysis Trial (PEITHO) do not support widespread use of thrombolytics in this scenario [18]. As such, the most recent American College of Chest Physicians guidelines recommend against systemically administered thrombolytic therapy in most patients with acute PE not associated with hypotension [5].

Surprisingly, $92 \%$ of the patients who had a contraindication to anticoagulant therapy did not receive an inferior vena cava filter. In patients with acute symptomatic VTE and known significant bleeding risk, a registry-based study suggested that inferior vena cava filter therapy might reduce the risk of PE-related mortality compared to anticoagulant therapy [19]. While some studies have found an overuse of inferior vena cava filters [20], others have suggested their underuse in patients with acute PE [21]. Though guidelines mainly limit their recommendation for inferior vena cava filter insertion to patients with acute symptomatic VTE and a contraindication to anticoagulation, the term "contraindication to anticoagulation" is not well defined and widely open to interpretation and, as such, might have accounted for underuse of filters in patients with $\mathrm{PE}$ and a significant bleeding risk [22]. Other reasons might include clinicians' fear of filter-related complications combined with anticipated low retrieval rates.

The strengths of our study include its prospective nature and adjudication of outcomes, the large number of patients and the high rate of completed follow-up. Use of the consecutive single hospital cohort and the RIETE validation cohort allowed for analyses of the causes and clinical consequences of everyday management practice for acute PE. However, the findings of this study should be interpreted in light of the following limitations. First, our study is observational and nonrandomized. The association between non-adherent management and outcomes does not necessarily prove casualty and may have been affected by certain prognostic factors and unmeasured confounders. Additionally, our conclusions are limited to the specific indications that we used for defining deviation from guidelines (i.e. anticoagulation with UFH, use of thrombolytics and use of inferior vena cava filters) and it will be important to assess whether these findings can be translated across other therapeutic strategies (e.g. anticoagulation with direct oral anticoagulants). Second, the criteria for adherence may be questioned because some strategies are not universally accepted. For example, the earlier sets of guidelines were more discretionary about the use of thrombolytic therapy in patients with haemodynamically stable PE [4]. However, as discussed above, recent evidence did not concur with permissive use of thrombolytic therapy and this was incorporated into subsequent guidelines $[5,6]$. Furthermore, the vast majority of non-adherence in our study stemmed from potential "underuse" in clinical scenarios where guidelines from different societies are in agreement.

In conclusion, management that does not adhere to evidence-based guidelines for three major indications related to anticoagulation, use of thrombolytics and use inferior vena cava filters frequently occurred, and was associated with worse outcomes in patients with acute PE. Future research should focus on determining how to implement guidelines adherence to help improve outcomes and minimise waste. Professional societies and policymakers can help institute strategies to monitor adherence to recommendations and quality improvement initiatives to address the major areas of concern [23]. Institutions should concentrate on strategies that can help optimise implementation of internationally recognised guidelines. Physicians, in turn, should pay more attention to haemodynamically unstable patients and those who have risk factors for bleeding because of their high risk for receiving non-adherent management for their acute PE and their high risk for associated adverse outcomes.

Acknowledgements: We thank the RIETE Registry Coordinating Center, the S\&H Medical Science Service, for their quality control data, logistic support and administrative support.

Support statement: Sanofi Spain supported the RIETE Registry with an unrestricted educational grant. Bayer Pharma AG supported the part of the RIETE Registry outside Spain, which accounted for $24.39 \%$ of the total patients included in the Registry. Funding information for this article has been deposited with the Crossref Funder Registry

Author contributions: D. Jiménez, D. Barrios, R.D. Yusen and M. Monreal conceived and designed the study; D. Jiménez, B. Bikdeli, D. Barrios, R. Morillo, R. Nieto, I. Guerassimova, A. Muriel, L. Jara-Palomares, L. Moores, V. Tapson, R.D. Yusen and M. Monreal acquired, analysed and interpreted the data; D. Jiménez, B. Bikdeli, D. Barrios, R. Morillo, R. Nieto, I. Guerassimova, A. Muriel, L. Jara-Palomares, L. Moores, V. Tapson, R.D. Yusen and M. Monreal critically revised the manuscript for important intellectual content; and D. Jiménez, R.D. Yusen and M. Monreal supervised the study. The corresponding author, D. Jiménez, had full access to all of the data in the study and had final responsibility for the decision to submit for publication.

Members of the RIETE Group: Argentina: Gutiérrez P, Vázquez FJ, Vilaseca A; Belgium: Vanassche T, Vandenbriele C, Verhamme P; Brazil: Yoo HHB; Canada: Wells P; Czech Republic: Hirmerova J, Malý R; Ecuador: Salgado E; France: Benzidia I, Bertoletti L, Bura-Riviere A, Falvo N, Farge-Bancel D, Hij A, Merah A, Mahé I, Moustafa F, Quere I; Israel: Braester A, Brenner B, Ellis M, Tzoran I; Italy: Bilora F, Bucherini E, Cattabiani C, Ciammaichella M, Dentali F, Di Micco P, Giorgi-Pierfranceschi M, Grandone E, Imbalzano E, Lessiani G, Maida R, Mastroiacovo D, Mumoli N, Pace F, Pesavento R, Pinelli M, Prandoni P, Quintavalla R, Rocci A, Siniscalchi C, Tiraferri E, Tonello D, Visonà A, Zalunardo B; 
Latvia: Gibietis V, Kigitovica D, Skride A; FYR Macedonia: Zdraveska M; Spain: Adarraga MD, Aibar MA, Alfonso M, Ara J, Arcelus JI, Ballaz A, Baños P, Barba R, Barrón M, Barrón-Andrés B, Bascuñana J, Blanco-Molina A, Camon AM, Carrasco C, Chasco L, Cruz AJ, de Miguel J, del Pozo R, del Toro J, Díaz-Pedroche MC, Díaz-Peromingo JA, Falgá C, Fernández-Capitán C, Fernández-Muixi J, Fidalgo MA, Font C, Font L, Furest I, García MA, García-Bragado F, García-Morillo M, García-Ortega A, García-Raso A, García-Ródenas M, Gavín O, Gómez C, Gómez V, González J, Grau E, Guijarro R, Gutiérrez J, Hernández-Blasco L, Hernando E, Isern V, Jara-Palomares L, Jaras MJ, Jiménez D, Jiménez-Cano S, Joya MD, Lima J, Llamas P, Lobo JL, López-Jiménez L, López-Reyes R, López-Sáez JB, Lorente MA, Lorenzo A, Loring M, Lumbierres M, Madridano O, Maestre A, Marchena PJ, Martín M, Martín-Martos F, Martínez MP, Monreal M, Mora JM, Morales MV, Nieto JA, Núñez MJ, Olivares MC, Otalora S, Otero R, Pedrajas JM, Pellejero G, Pérez-Ductor C, Peris ML, Pons I, Porras JA, Riera-Mestre A, Rivas A, Rodríguez-Dávila MA, Rodríguez-Galán I, Rosa V, Rubio CM, Ruiz-Artacho P, Sahuquillo JC, Sala-Sainz MC, Sampériz A, Sánchez-Martínez R, Sancho T, Soler S, Soto MJ, Suriñach JM, Tolosa C, Torres MI, Trujillo-Santos J, Uresandi F, Usandizaga E, Valero B, Valle R, Vela J, Vidal G, Villalobos A, Xifre B; Switzerland: Bounameaux H, Calanca L, Erdmann A, Mazzolai L; USA: Bikdeli B.

Conflict of interest: None declared.

\section{References}

1 Bĕlohlávek J, Dytrych V, Linhart A. Pulmonary embolism, part I: epidemiology, risk factors and risk stratification, pathophysiology, clinical presentation, diagnosis and nonthrombotic pulmonary embolism. Exp Clin Cardiol 2013. 18: $129-138$

2 Silverstein MD, Heit JA, Mohr DN, et al. Trends in the incidence of deep vein thrombosis and pulmonary embolism: a 25-year population-based study. Arch Intern Med 1998; 158: 585-593.

3 Heit JA. The epidemiology of venous thromboembolism in the community. Arterioscler Thromb Vasc Biol 2008; 28: $370-372$.

4 Jaff MR, McMurtry MS, Archer SL, et al. Mangement of massive and submassive pulmonary embolism, iliofemoral deep vein thrombosis, and chronic thromboembolic pulmonary hypertension: a scientific statement from the American Heart Association. Circulation 2011; 123: 1788-1830.

5 Kearon C, Akl EA, Ornelas J, et al. Antithrombotic therapy for VTE disease: CHEST guideline and expert panel report. Chest 2016; 149: 315-352.

6 Konstantinides SV, Torbicki A, Agnelli G, et al. 2014 ESC Guidelines on the diagnosis and management of acute pulmonary embolism. Eur Heart J 2014; 35: 3033-3073.

7 Pronovost PJ. Enhancing physicians' use of clinical guidelines. JAMA 2013; 310: 2501-2502.

8 Cabana MD, Rand CS, Powe NR, et al. Why don't physicians follow clinical practice guidelines? A framework for improvement. JAMA 1999; 282: 1458-1465.

9 Von Elm E, Altman DG, Egger M, et al. The strengthening the reporting of observational studies in epidemiology (STROBE) statement: guidelines for reporting observational studies. Ann Intern Med 2007; 147: 573-577.

10 Remy-Jardin M, Remy J, Wattinne L, et al. Central pulmonary thromboembolism: diagnosis with spiral volumetric CT with the single-breath-hold-technique-comparison with pulmonary angiography. Radiology 1992; 185: 381-387.

11 PIOPED Investigators. Value of ventilation/perfusion scan in acute pulmonary embolism: results of the prospective investigation of the pulmonary embolism diagnosis (PIOPED). JAMA 1990; 263: 2753-2759.

12 Kearon C, Ginsberg JS, Hirsh J. The role of venous ultrasonography in the diagnosis of suspected deep venous thrombosis and pulmonary embolism. Ann Intern Med 1998; 129: 1044-1049.

13 Kearon C, Kahn SR, Agnelli G, et al. Antithrombotic therapy for venous thromboembolic disease. American College of Chest Physicians Evidence-Based Clinical Practice Guidelines (8th Edition). Chest 2008; 133: 6 Suppl., 454S-545S.

14 Prandoni P, Cogo A, Bernardi E, et al. A simple approach for detection of recurrent proximal vein thrombosis. Circulation 1993; 88: 1730-1735.

15 Riera-Mestre A, Jiménez D, Muriel A, et al. Thrombolytic therapy and outcome of patients with an acute symptomatic pulmonary embolism. J Thromb Haemost 2012; 10: 751-759.

16 Kaplan EL, Meier P. Nonparametric estimation from incomplete observations. J Am Stat Assoc 1958; 53: 457-481.

17 Jiménez D, de Miguel-Díez J, Guijarro R, et al. Trends in the management and outcomes of acute pulmonary embolism: analysis from the RIETE registry. J Am Coll Cardiol 2016; 67: 162-170.

18 Meyer G, Vicaut E, Danays T, et al. Fibrinolysis for patients with intermediate-risk pulmonary embolism. $N$ Engl J Med 2014; 370: 1402-1411.

19 Muriel A, Jiménez D, Aujesky D, et al. Survival effects of inferior vena cava filter in patients with acute symptomatic venous thromboembolism and a significant bleeding risk. J Am Coll Cardiol 2014; 63: 1675-1683.

20 Bikdeli B, Wang Y, Minges KE, et al. Vena caval filter utilization and outcomes in pulmonary embolism: medicare hospitalizations from 1999 to 2010. J Am Coll Cardiol 2016; 67: 1027-1035.

21 Baadh AS, Zikria JF, Rivoli S, et al. Indications for inferior vena cava filter placement: do physicians comply with guidelines? J Vasc Interv Radiol 2012; 23: 989-995.

22 Lessne ML, Sing RF. COUNTERPOINT: do the benefits outweight the risks for most patients under consideration for inferior vena cava filters? No. Chest 2016; 150: 1182-1184.

23 Faxon DP, Schwamm LH, Pasternak RC, et al. Improving quality of care through disease management: principles and recommendations from the American Heart Association's Expert Panel on Disease Management. Circulation 2004; 109: 2651-2654. 